\title{
Visual analogue scale: a simple tool in rural region for physician's global evaluation and patient's self-evaluation in allergic rhinitis
}

\author{
Ganesh S. Pentewar*, Ranjit J. Wagh, Aparna S. Chincholkar
}

Department of Pharmacology, MIMER Medical College, Talegaon Dabhade, Maharashtra, India

\author{
Received: 31 March 2020 \\ Revised: 05 May 2020 \\ Accepted: 07 May 2020 \\ *Correspondence: \\ Dr. Ganesh S. Pentewar, \\ Email: drpentewarganesh@gmail.com
}

Copyright: () the author(s), publisher and licensee Medip Academy. This is an open-access article distributed under the terms of the Creative Commons Attribution Non-Commercial License, which permits unrestricted non-commercial use, distribution, and reproduction in any medium, provided the original work is properly cited.

\begin{abstract}
Background: The study was done with the objective to study whether the physician's global evaluation of the consultation corelates with patient's self-evaluation to patient outcome concerning symptom relief of nasal congestion by using visual analogue scale.

Methods: A total of 52 patients completed a visual analogue score questionnaire presented at the consultation. 52 patients were reached in a seven days follow-up after the consultation. Patient's outcome measures conducted at MIMER Medical College and Dr. Bhausaheb Sardesai Hospital in rural Maval Taluka in Pune district of Maharashtra state.

Results: Physician's self-evaluation of the consultation was much more strongly associated with outcome than the patient's evaluation.

Conclusions: The difference between the physician's and patient's evaluation of the consultation to predict patient outcomes indicates that the physician's self-evaluation of the consultation is of importance.
\end{abstract}

Keywords: Allergic rhinitis, Physician's global evaluation, Patient's self-evaluation, Visual analogue scale

\section{INTRODUCTION}

Allergic rhinitis (AR) is an IgE-mediated chronic disease induced by environmental allergens due to hypersensitivity reaction of nasal mucosa which is characterized by sneezing, itching, watery nasal discharge and nasal obstruction. Release of various mediators from mast cells, eosinophils, basophils and neutrophils are responsible for the symptoms of allergic rhinitis. ${ }^{1}$ Continuous assessment and monitoring of allergic rhinitis symptom severity depends on the place and time in which they occur whereas allergic rhinitis symptoms are often subjective and difficult to assess and verify. Individualised therapy and continuous monitoring of the disease create the need for a simple and effective tool. Visual analogue scales (VAS) is measuring scale for disease related symptom in patient to classify the severity of symptom and treatment monitoring. For better evaluation of allergic rhinitis symptoms patient specify a point on the scale that best corresponds to the individual severity of symptoms. VAS is useful for documentation of AR severity of symptom and monitoring of course of treatment. Simple tool to distinguish in minimal differences in symptom severity, simplicity and easy interpretation. VAS has been used effectively in both seasonal as well as perennial allergic rhinitis. ${ }^{2}$

Physician global evaluation is one of the most widely reported patient related outcomes and this evaluation are used in day today clinical practice for patient's perspective on their clinical condition or their overall health status. Their incorporation into clinical practice of AR has both psychological and social impact. Physician evaluation is very useful work tool for diagnosis and management of AR and for better evaluation for change in treatment. ${ }^{3,4}$ It is important to know different 
parameters of consultation and their degree of importance to the patient. The ultimate aim of any consultation and subsequent treatment with antiallergic drugs is patient's compliance, safety profile, improvement in severity of symptom and better use of more effective drugs. For successful therapy of AR, physician's global evaluation is more accessible than patient's self-evaluation. ${ }^{5,6}$

\section{Aim and objective}

The objective of the study was to determine whether the physician's global evaluation of the consultation corelates with patient's self-evaluation to patient outcome concerning symptom relief of nasal congestion by using visual analogue scale.

\section{METHODS}

The present study is single centered, open label, randomized, four arm, parallel-group, comparative clinical study between orally administered cetirizine, levocetirizine, loratadine and fexofenatidine in patients with allergic rhinitis (AR). The study was conducted at MIMER Medical College and Dr. Bhausaheb Sardesai Hospital in rural Maval Taluka in Pune district of Maharashtra state and study period is July to December 2012.

\section{Enrolment}

AR patients were identified from the ear nose and throat outpatient department (ENT OPD). Once identified, they were briefed about the study and activities. If they were apparently willing to take part in the study, a copy of a patient information sheet and informed consent form was given to patient. The study was approved by Institutional Ethical Committee and procedures followed in this study were accordance with the ethical standard laid down by Indian Council of Medical Research (ICMR). They were given adequate time to decide to take part in the study , and if willing, a written informed consent was taken from all the patients participated in the study after explaining the patient's diagnosis, the nature and purpose of a proposed treatment, the risks and benefits of a proposed treatment and alternative treatment. Study related activity was started only after obtaining the informed consent form.

The process was documented in the source notes. When the physician considered a patient fulfilled the inclusion criteria, the patient was asked to participate directly after the consultation. Patients were informed verbally and in writing of confidentiality that participation was voluntary and that if they decided to participate, they would be called for follow up after 7 days consultation regarding their current state of health.

The patient was then asked to complete the VAS in the waiting room directly after the consultation. The physician's VAS questionnaire could be matched with the corresponding patient VAS. Patients were asked if they would accept follow up after 7 days. If they accepted, they were asked about their current health status regarding problems discussed with the physician 7 days earlier.

\section{Inclusion criteria}

Inclusion criteria were patients with a clinical history of AR, patients aged above 18 years inclusive of either sex. Nasal congestion severity score (NCSS) must be at least 3 at screening. Patient with ability to understand and sign written informed consent form, which must have been obtained prior to screening. Patients willing to comply with the protocol requirements.

\section{Exclusion criteria}

Exclusion criteria were patients with history of any one of the following criteria at baseline had not been considered for the study. Known hypersensitivity to antihistaminics, concomitant medications that could affect the efficacy of study drugs, antibiotics for acute conditions within 2 weeks of the first visit, and pregnant or lactating women.

\section{Randomization}

At the baseline visit, after confirming the study subjects who fulfilled the eligibility criteria and returned the duly signed Informed consent forms, a total of 52 patients (13 per each group) were assigned sequentially to each of the 4 study groups.

All the study patients received their respective medication orally daily in the evening for 1-week period. Group 1 received tab cetirizine hydrochloride $10 \mathrm{mg}$, group 2 patients was given with tab levocetirizine hydrochloride $5 \mathrm{mg}$, group 3 received tab loratadine 10 $\mathrm{mg}$, and group 4 received tab fexofenadine hydrochloride $120 \mathrm{mg}$.

\section{Visit 1}

Baseline screening and randomization to study treatment group (day 1). Following procedures were performed on the first day of the subject enrolment that include medical history, physical examination and vital signs, patient recording in patient diary (nasal symptoms score), and issue of study medications for 1 -week treatment.

\section{Visit 2}

At the end of study on day 8 following procedures were performed on the eighth day that include physical examination and vital signs, patient recording in patient diary (nasal symptoms score), patent's self-evaluation for overall response to treatment, and physician's global evaluation for overall response to treatment. 


\section{Efficacy assessment}

Physician's global evaluation for overall response to treatment at the end of treatment

At the end of the treatment, the physician was asked to complete a single global evaluation question regarding the patient's allergic rhinitis, based on a straightforward clinical assessment on the patient's clinical status and using the therapeutic response scale at the end of the treatment compared with baseline, without reference to the patient's diaries.

Patient's self-evaluation for overall response to treatment at the end of treatment

Patients were provided with visual analogue scale for patent's self-evaluation for overall response. This was filled by patient at the time of screening and randomization visit to obtain the baseline and study score. At the end of the treatment, the patient was asked to complete a self-evaluation for response to treatment based on the clinical status using visual analogue symptom scale and using the therapeutic response scale at the end of the treatment from baseline.

Figure 1: Patient's self-evaluation and physician's global evaluation scale (therapeutic response scale), ${ }^{7,8}$

\begin{tabular}{|c|c|c|}
\hline Score & Grade & Description \\
\hline 1 & Complete relief & $\begin{array}{l}\text { Virtually no symptoms } \\
\text { present }\end{array}$ \\
\hline 2 & Marked relief & $\begin{array}{l}\text { Symptoms are greatly } \\
\text { improved and although } \\
\text { present, are scarcely } \\
\text { troublesome }\end{array}$ \\
\hline 3 & Moderate relief & $\begin{array}{l}\text { Symptoms are present } \\
\text { may be troublesome but } \\
\text { are noticeably improved }\end{array}$ \\
\hline 4 & Slight relief & $\begin{array}{l}\text { Symptoms are present and } \\
\text { only minimal } \\
\text { improvement has been } \\
\text { obtained }\end{array}$ \\
\hline 5 & Treatment failure & $\begin{array}{l}\text { No reliefs, symptoms } \\
\text { unchanged or worse than } \\
\text { pre-treatment baseline }\end{array}$ \\
\hline
\end{tabular}

\section{Visual analogue scale}

Based on studies of aspects important to the patient in the consultation a questionnaire with 5 items was constructed. Items were constructed as statements with degrees of agreement recorded on a five points scale. Items represented both global and specific aspects of the consultation.

Adherence assessment: compliance to study medication and patient diary entries should be strictly verified during follow-up visit.

\section{Statistical analysis}

Changes in health, and responses to items in the VAS lack equidistant scale steps. The relationship between each statement in the VAS and changes in health outcome were analysed. Statistical analysis was performed using the statistical software microsoft SPSS 19.0. (SPSS Inc., Chicago, USA). Data was summarized using mean, median and standard deviation, 'Paired t' test was used to compare mean changes in patients before and after treatment. Probability $<0.05$ was considered statistically significant. Analysis of variance (ANOVA) was used to compare treatment groups for the quantitative primary and secondary outcomes. The statistician was blinded to the groups during analysis.

\section{RESULTS}

52 patients fulfilled the inclusion criteria and were invited to participate, 13 in each groups of the age group 18 to 65 years (mean age, $33.73 \pm 10.23$ years) were randomized and received either cetirizine, levocetirizine, loratadine, or fexofenadine over a period of one week. Mean compliance with treatment was $100 \%$ for all four treatment groups.

The response rate of the VAS among physicians was $100 \%(52 / 52)$ and among patients were also $100 \%$ (52/52). 7 days after the consultation $0 \%$ felt treatment failure, $2.5 \%$ felt a slight relief, $4.5 \%$ felt moderate relief, $23 \%$ felt a marked relief, and $70 \%$ felt complete relief concerning the problem they had discussed at the consultation (Table 1 and 2).

Table 1: Comparison of physician's global evaluation score between treatment groups at the end of treatment.

\begin{tabular}{|lllllll|}
\hline Groups $(\mathbf{n}=13)$ & Group 1 & Group 2 & Group 3 & Group 4 & F value & P value \\
\hline Physician's global evaluation score & $2.46 \pm 0.51$ & $1.69 \pm 0.75$ & $2.23 \pm 0.59$ & $2 \pm 0.82$ & 3.065 & $0.037 *$ \\
\hline
\end{tabular}

The values are expressed as mean $\pm \mathrm{SD}, \mathrm{n}=13$ patients in each group, *significant at $\mathrm{p}<0.05$ when compared between treatment groups using one-way ANOVA.

Table 2: Comparison of patient's self-evaluation score between treatment groups at the end of treatment.

\begin{tabular}{|lllllll|}
\hline Groups(n=13) & Group 1 & Group 2 & Group 3 & Group 4 & F value & P value \\
\hline Patient's self-evaluation score & $2.30 \pm 0.75$ & $1.77 \pm 0.83$ & $2.15 \pm 0.80$ & $2.07 \pm 0.86$ & 1.005 & 0.399 \\
\hline
\end{tabular}

The values are expressed as mean $\pm \mathrm{SD}, \mathrm{n}=13$ patient in each group. 
The physician's response to statements could indicate the patient's perceived change in health status 7 days after the consultation (Table 1). However, the patient's response to statements could not indicate the patient's perceived change in health status as well as the physician responses (Table 2 ).

\section{DISCUSSION}

The present study is carried out in the patients of allergic rhinitis, visiting ENT OPD. Physician's global evaluation and patient's self-evaluation for overall response to treatment based on the clinical status using visual analogue scale. Cetirizine did not prove any superior to other antihistaminics in clinical efficacy but it was equally effective in controlling the nasal congestion. Levocetirizine appears to be statistically significantly effective and offers relief from nasal congestion within a week. Therapeutic assessment between physician and patient, indicates the same degree of satisfaction with the overall effectiveness of the treatment. From the analysis of present comparative clinical study results show that both levocetirizine and loratadine control the symptoms of AR better as compared to cetirizine and fexofenadine but levocetirizine is a better choice in allergic rhinitis in comparison to others due to its safety profile.

The results of this study corroborate with those of a previous study done by Horak et al, in which monotherapy with levocetirizine is found to be significantly more effective in lowering the nasal symptom score and more effective than fexofenadine at and later than 22 hours after drug intake, an indication of the longer-duration of action of levocetirizine. ${ }^{9}$ Stubner et al study also concluded that levocetirizine is superior to loratadine in improving symptoms in seasonal allergic rhinitis and that there is a similar trend in perineal allergic rhinitis. ${ }^{10}$ In Shariat et al study, levocetirizine improves nasal congestion and rhinorrhea, the most prevalent and troublesome symptom in patients of AR which results in nasal obstruction during night which cause frequent awakening, sleep obstruction apnea, snoring, and sleep quality decrease. Such sleep quality decrease causes daily fatigue and daily drowsiness. ${ }^{11}$

\section{Safety analysis}

In the present study all drugs are well tolerated without any serious adverse effects. Therapeutic response scale of physician's global evaluation and patient's selfevaluation is in between complete to marked relief of symptoms in the levocetirizine compared to other treatment group (Table 1 and 2).

\section{CONCLUSION}

In this study we were able to demonstrate a relationship between the process in the consultation as perceived by the physicians and outcome in terms of change in health. Patient's satisfaction is very important parameter in the quality of consultation and treatment. This study indicates a relationship between the physician's global evaluation of the process in the consultation and patient outcome that should be clarified in future studies. VAS seems to be suited as a self-evaluation tool for physicians as well as patient.

\section{ACKNOWLEDGEMENTS}

Thanks, are offered to patients for participating in the study. I am grateful to Mrs. Raje Swati, Assistant Professor, Department of Community Medicine who has provided for valuable discussions about statistics.

Funding: No funding sources

Conflict of interest: None declared

Ethical approval: The study was approved by the Institutional Ethics Committee

\section{REFERENCES}

1. Wallace DV, Dykewicz MS, Bernstein DI, Moore JB, Cox L, Khan DA, et al. The diagnosis and management of rhinitis: An updated practice parameter. J Allergy Clin Immunology. 2008;122:184.

2. Aitken RC. Measurement of feelings using visual analogue scales. Proc R Soc Med. 1969;62:989-93.

3. Arborelius E, Timpka T, Nyce JM. Patients' comment on video recorded consultations: the "good" GP and the "bad". Scand J Soc Med. 1992;20:213-6.

4. Anden A, Andersson SO, Rudebeck CE. Satisfaction is not all: Patients' perceptions of outcome of general practice consultations, a qualitative study. BMC Fam Pract. 2005;6:43.

5. Anden A, Andersson SO, Rudebeck CE. Concepts underlying outcome measures in studies of consultations in general practice. Scand $\mathrm{J}$ Prim Health Care. 2006;24:218-23.

6. Ahlen GC, Gunnarsson RK. The physician's selfevaluation of the consultation and patient outcome: A longitudinal study. Scandinavian J Primary Health Care. 2013;31:26-30.

7. Demoly P, Bousquet PJ, Mesbah K, Bosquet J, Devillier P. Visual analogue scale in patients treated for allergic rhinitis: an observational prospective study in primary care: asthma and rhinitis. Clin Exp Allergy. 2013;43(8):881-8.

8. Juniper EF, Stahl E, Doty RL, Simons FE, Allen DB, Howarth PH. Clinical outcomes and adverse effect monitoring in allergic rhinitis. $\mathbf{J}$ Allergy Clin Immunol. 2005;115(3):390-413.

9. Horak F, Zieglmayer PU, Zieglmayer R, Kavina A, Leme P. Levocetirizine has a longer duration of action on improving total nasal symptoms score than fexofenadine after single administration. Br J Clin Pharmacol. 2005;60(1):24-31.

10. Stubner P, Zieglmayer R, Horak F. A direct comparison of the efficacy of antihistamines in SAR 
and PAR: randomised, placebo-controlled studies with levocetirizine and loratadine using an environmental exposure unit - the Vienna Challenge Chamber (VCC). Curr Med Res Opin. 2004;20(6):891-902.

11. Kalmarzi RN, Khazaei Z, Shahsavar J, Gharibi F, Tavakol M, Khazaei S, et al. The impact of allergic rhinitis on quality of life: a study in western Iran. Biomed Res Ther. 2017;4(9):1629-37.
Cite this article as: Pentewar GS, Wagh RJ,

Chincholkar AS. Visual analogue scale: a simple tool in rural region for physician's global evaluation and patient's self-evaluation in allergic rhinitis. Int $\mathbf{J}$ Basic Clin Pharmacol 2020;9:951-5. 